\title{
Periodic Methylation Patterns in the Background Mucosa of Gastric Cancer
}

\author{
Sang-Woong $\mathrm{Kim}^{1}{ }^{1} *$, Jung-Hwan $\mathrm{Oh}^{2}{ }^{2 *}$, Tae Ho Kim², Joon-Sung Kim², Seung-Jin Hong ${ }^{1}$ \\ Departments of Microbiology ${ }^{1}$ and Internal Medicine ${ }^{2}$, College of Medicine, The Catholic University of Korea, Seoul, Korea
}

\begin{abstract}
Background/Aims: Gastrointestinal glandular stem cells renew every 8 years. New stem cells with impeded housekeeping gene methylation have unstable phenotypes and are prone to transform into malignant cells. Age-related changes in methylation in the gastric mucosa were evaluated to define the period of cancer-prone stem cell replacement.

Materials and Methods: Endoscopic biopsy specimens of normal-appearing gastric mucosa were obtained from 148 Helicobacter pylori-negative controls, $124 \mathrm{H}$. pylori-positive controls, and 69 gastric cancer patients with closed-type mucosal atrophy. Methylation-variable sites of two stomach-specific genes (TFF2 and TFF3) and four housekeeping genes (CDH1, ARRDC4, MMP2, and $C D K N 2 A$ ) were analyzed using radioisotope-labeled methylation-specific polymerase chain reaction. Age-related methylation was evaluated depending on the gastric mucosal atrophy at 2-year intervals.

Results: TFF2 methylation peaked periodically at 40 to 41,48 to 49, 56 to 57 , and 64 to 65 years of age in $H$. pylori-negative controls Periodic peaks of TFF2 methylation were also found in $H$. pylori-positive controls. Housekeeping-gene methylation troughed at 48 to 49, 56 to 57, and 68 to 69 years of age in cancer patients. Trough methylation of $C D H 1$ and ARRDC4 was lower in cancer patients than in H. pylori-positive controls.

Conclusions: Methylation peaks of stomach-specific TFF2 in controls and methylation troughs of housekeeping genes in cancer patients were found every 8 years. Periodic methylation patterns may be used to identify individuals at high risk for gastric cancer.
\end{abstract} (Korean J Helicobacter Up Gastrointest Res 2019;19:48-55)

Key Words: Adult stem cells; DNA methylation; Gastric cancer

\section{INTRODUCTION}

Old gastric stem cells that lose their renewal capacity need to be replaced with new stem cells as a part of the aging process. ${ }^{1,2}$ An age-related methylation study demonstrated that in humans with a relatively long lifespan, old colonic stem cells are replaced with new stem cells every 8 years. ${ }^{3,4}$ Newly replaced stem cells with unstable phenotypes are stabilized by housekeeping gene methylation. ${ }^{5-8}$ When phenotype-stabilizing methylation is impeded, new stem cells may experience reactive intrinsic migration and transform into malignant cells. In our previous study of

\footnotetext{
Received: November 19, 2018 Revised: November 23, 2018 Accepted: November 26, 2018

Corresponding author: Seung-Jin Hong

Department of Microbiology, College of Medicine, The Catholic University of Korea, 222 Banpo-daero, Seocho-gu, Seoul 06591, Korea

Tel: +82-2-2258-7344, Fax: +82-2-596-8969, E-mail: hongsjin@catholic.ac.kr

*These authors contributed equally to this work.

This study was funded by Basic Science Research Program through the National Research Foundation of Korea funded by the Ministry of Education (2015R1D 1A101059548) and Catholic Medical Center Research Foundation made in the program year of 2017 (5-2017-B0001-00018)

We sincerely thank Hye-Jung Lee and Ji-Yon Jang (The Catholic University of Korea) for their excellent technical assistance.
}

the gastric mucosa, housekeeping gene methylation was impeded in patients with gastric cancer for an average of 8 years. $^{8}$ The self-renewal capacity of gastric mucosal glandular stem cells appears to be restored periodically. Age-specific methylation patterns could provide a clue to distinguish individuals at high-risk for gastric cancer during the period of stem cell replacement.

Methylation-variable regions are different between housekeeping genes and tissue-specific genes. ${ }^{9}$ In housekeeping genes containing $\mathrm{CpG}$ islands, $\mathrm{CpG}-\mathrm{island}$ margins display more wide ranges of methylation variations compared to $\mathrm{CpG}$-island centers, and their methylation is influenced by the types and the distances of gene-adjacent retroelements. ${ }^{9,10}$ Tissue-specific genes lacking CpG islands showed variable methylation near the transcriptional start sites under the influence of their expression. Variable methylation regions of tissue-specific and housekeeping genes are termed transitional-CpG sites. ${ }^{7,1}$ Previous methylation studies of the stomach have focused on the association between CpG-island center methylation and tumor-suppressor gene inactivation. However,

Copyright $\odot 2019$ Korean College of Helicobacter and Upper Gastrointestinal Research

@ The Korean Journal of Helicobacter and Upper Gastrointestinal Research is an Open-Access Journal. All articles are distributed under the terms of the Creative Commons Attribution Non-Commercial License (http://creativecommons.org/licenses/by-nc/4.0) which permits unrestricted non-commercial use, distribution, and reproduction in any medium, provided the original work is properly cited. 
the inactivation role of $\mathrm{CpG}$-island methylation during gastric carcinogenesis is unclear. For instance, allele-specific hypermethylation of the $C D H 1$ gene is uncommon in familial or sporadic gastric cancer with loss of $C D H 1$ expression. ${ }^{12}$ Additionally, housekeeping genes are more frequently methylated in subjects infected with Helicobacter pylori than in gastric cancer patients. ${ }^{13}$ Transitional-CpG methylation may be associated with the stabilization of stem cell phenotypes. ${ }^{14,15}$ New stem cells fixed in the gastric mucosa acquire the phenotypes of gastric stem cells through high expression of stomach-specific genes and fine down-regulation of numerous housekeeping genes. Down-regulated housekeeping genes are stabilized by cell division-dependent methylation. ${ }^{16,17}$ Therefore, clonal expansion of new stem cells is likely to be estimated by analyzing the transitional $\mathrm{CpG}$ methylation of stomach-specific and housekeeping genes.

This study aimed to evaluate the period of cancer-prone stem cell replacement. Transitional CpG methylation will change in accordance with the periodic replacement of new stem cells. ${ }^{7,8}$ Because $H$. pylori-associated gastric mucosal atrophy spreads from the gastric antrum to the body, the body sites are less affected by atrophy-related methylation inhibition. ${ }^{6}$ Agespecific changes in transitional CpG methylation in both the antrum and the body were analyzed in $H$. pylori-negative controls, H. pylori-positive controls, and patients with gastric cancer at 2-year intervals.

\section{MATERIALS AND METHODS}

\section{Endoscopic biopsy specimens}

Endoscopic biopsy specimens of normal gastric mucosa were obtained from St. Paul Hospital (Seoul, Korea), Bucheon St. Mary's Hospital (Bucheon, Korea), and Incheon St. Mary's Hospital (Incheon, Korea) between March 2008 and June 2016 and included in a methylation study. Paired mucosa specimens were biopsied from the lesser curvature of the antrum and the greater curvature of the middle body and stored immediately at $-70^{\circ} \mathrm{C}$. $\mathrm{H}$. pylori infection was determined using the Warthin-Starry silver impregnation method. The extent of gastric mucosal atrophy was classified into closed- and open-type gastric mucosal atrophy based on the endoscopic atrophic border score proposed by Kimura and Takemoto. ${ }^{18}$ The subjects with open-type mucosal atrophy were excluded in this study in order to discriminate past or long-term $H$. pylori infection.

\section{DNA extraction and bisulfite treatment}

DNA extraction and bisulfite treatment were performed as described elsewhere. ${ }^{6,9}$ In brief, biopsy specimens were dissolved in DNA extraction buffer (0.5\% Tween 20, 1 $\mathrm{mM}$ EDTA, $50 \mathrm{mM}$ Tris, and $0.5 \mathrm{mg} / \mathrm{mL}$ proteinase $\mathrm{K}$ ) for 24 hours at $37^{\circ} \mathrm{C}$. The extracted DNA samples were modified as follows: $21.5 \mu \mathrm{L}$ of genomic DNA were denatured in $3 \mathrm{M} \mathrm{NaOH}$ at $37^{\circ} \mathrm{C}$ for 15 minutes and subsequently treated with $2.3 \mathrm{M}$ sodium bisulfite and $10 \mathrm{mM}$ hydroquinone at $50^{\circ} \mathrm{C}$ for 12 hours. DNA was purified using Wizard DNA purification resin (Promega, Madison, WI, USA) and desulfonated with $3 \mathrm{M} \mathrm{NaOH}$ at $37^{\circ} \mathrm{C}$ for 15 minutes, precipitated with ethanol. DNA was dissolved in $40 \mu \mathrm{L}$ of $5 \mathrm{mM}$ Tris buffer.

\section{Methylation analysis of biopsy specimens}

Two stomach-specific genes (TFF2 and TFF3), two housekeeping genes adjacent to Alu retroelements ( $C D H 1$ and $A R R D C 4$ ), and two housekeeping genes adjacent to LTR retroelements (MMP2 and CDKN2A) were selected for the methylation analysis of small biopsy specimens. ${ }^{6,8}$ Methylation primers were designed to target the methylation-variable transitional-CpG sites between the transcriptional start sites and gene-adjacent retroelements. ${ }^{6,9,11}$

Methylation-specific polymerase chain reaction (MSP) was performed under stringent conditions with a hot start condition and radioisotope labeling to compensate for the low guanine-cytosine contents and repetitive sequences of transitional-CpG sites. ${ }^{6,9}, 19$ One microliter of bisulfite-treated DNA was mixed with $1 \mathrm{mCi}$ of $\alpha{ }^{-32} \mathrm{P}$ dTTP (PerkinElmer, Boston, MA, USA), $62.5 \mathrm{mM}$ each dATP, dCTP, and dGTP, $25 \mathrm{mM}$ dTTP, $1 \mathrm{pM}$ of primers, 0.1\% Tween 20, and 0.3 unit of Taq DNA polymerase (Takara, Kyoto, Japan). The reactions were subjected to thermal cycling as follows: denaturation at $99^{\circ} \mathrm{C}$ for $5 \mathrm{mi}-$ nutes followed by the addition of DNA polymerase and dNTP mixture; amplification for 32 cycles of $93^{\circ} \mathrm{C}$ for 50 
seconds, $53^{\circ} \mathrm{C}$ to $62^{\circ} \mathrm{C}$ for one minute, and $72^{\circ} \mathrm{C}$ for one minute; and extension at $72^{\circ} \mathrm{C}$ for 3 minutes. MSP products were separated by polyacrylamide gel electrophoresis and visualized by autoradiography with a radioluminograph scanner (PMI 170-9400; BioRad, Hercules, CA, USA). The band intensities were measured using TINA image software (Raytest Isotopenme $\beta$ gerate, Straubenhardt, Germany). Methylation values were scored as the proportion of band intensities of the methylation primer to the total band intensities of the methylation and unmethylation primers, and were stratified into 10 levels at $10 \%$ increments.

\section{Ethics statement}

The study of biopsy specimens was reviewed and approved by St. Paul's Hospital Institutional Review Board, the Catholic University of Korea (IRB no. PCMC08BR005 and XC15TIMI0044P). All participating subjects provided written informed consent prior to the study.
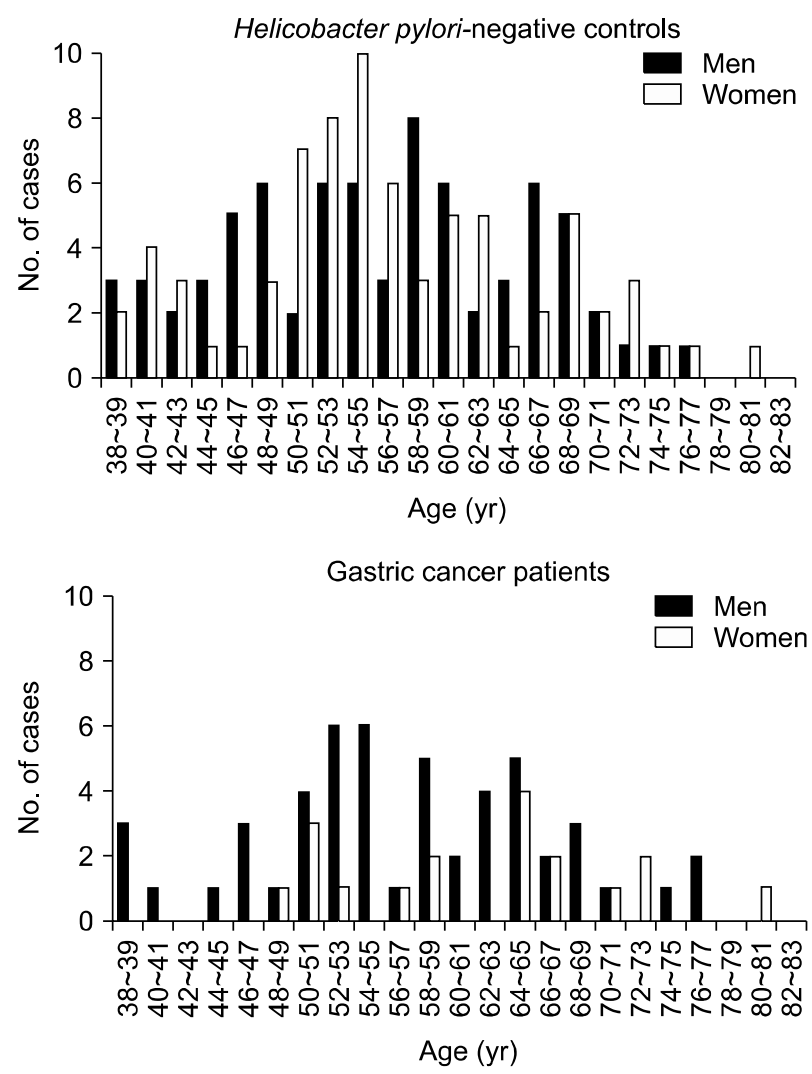

\section{RESULTS}

A total of $148 \mathrm{H}$. pylori-negative controls, $124 \mathrm{H}$. pylori-positive controls, and 69 cancer patients from 38 to 81 years of age were enrolled to perform methylation study on the normal gastric mucosa (Fig. 1). Cancer patients were not grouped by $H$. pylori infection because there were few differences in transitional-CpG methylation between $H$. pylori-positive and -negative cancer patients in previous studies. $^{6}$

Age-related changes in methylation were plotted at 2-year age intervals, and the periodic curves were evaluated during 8-year cycles (Fig. 2A). The TFF2 methylation curve tended to peak every 8 years, regardless of sex or $H$. pylori status. In samples from $H$. pylori-negative men, the TFF2 methylation curve exhibited five regular peaks at 40 to 41,48 to 49,56 to 57,64 to 65 , and 72 to 73 years of age. TFF2 methylation peaks were detected at 40 to 41,46 to 47,54 to 55 , and 64 to 65 years of age in H. pylori-positive men. The methylation of TFF3, which is specifically expressed in the antrum, was known

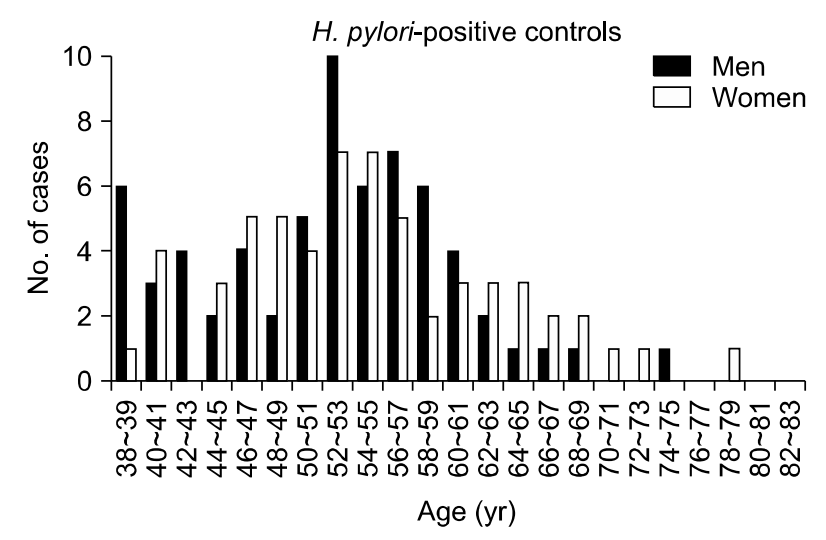

Fig. 1. Age distribution of subjects included in the transitional-CpG methylation analysis. Samples are collected at 2-year intervals. 
A

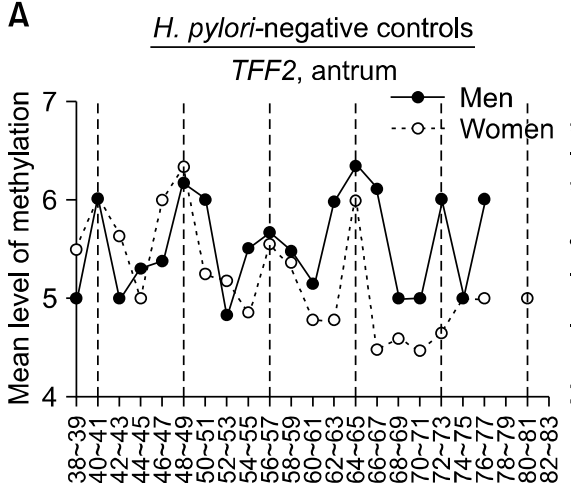

Age (yr)

TFF3, antrum

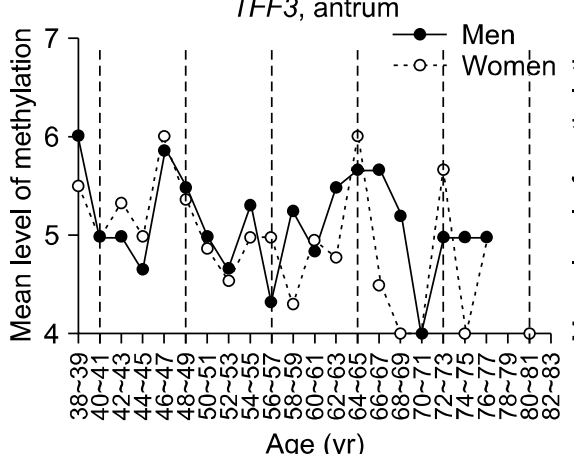

$C D H 1$ and $A R R D C 4$, body

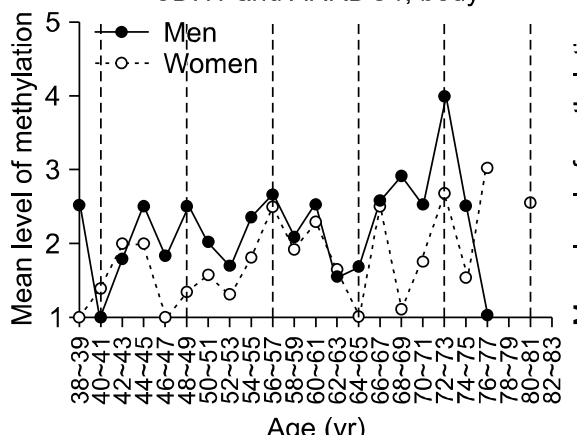

Age (yr)

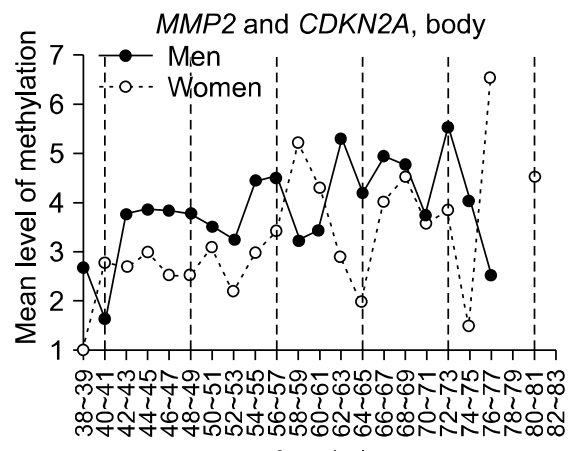

Age (yr)

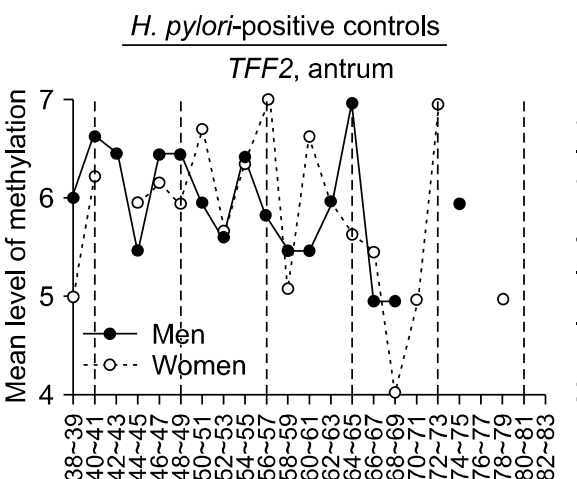

Age (yr)

TFF3, antrum

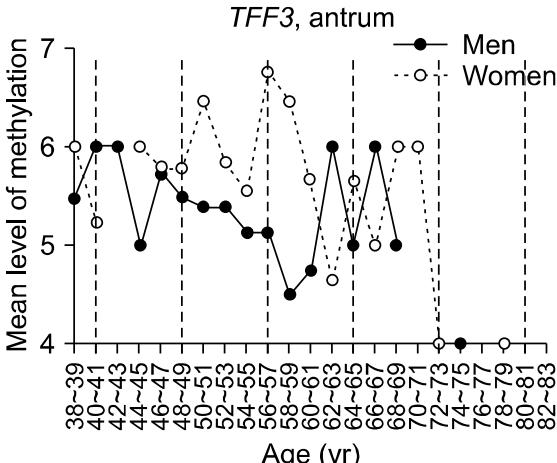

$C D H 1$ and $A R R D C 4$, body

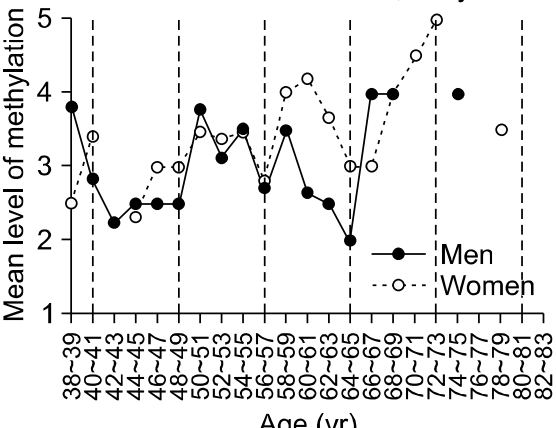

Age (yr)

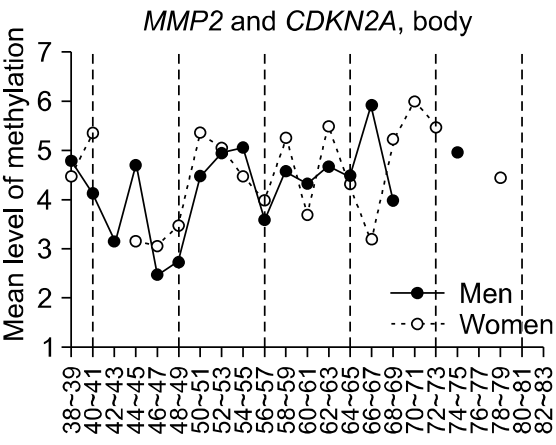

Age (yr)

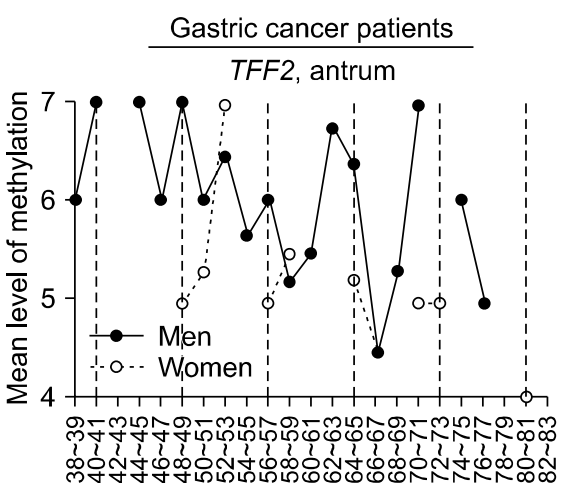

Age (yr)

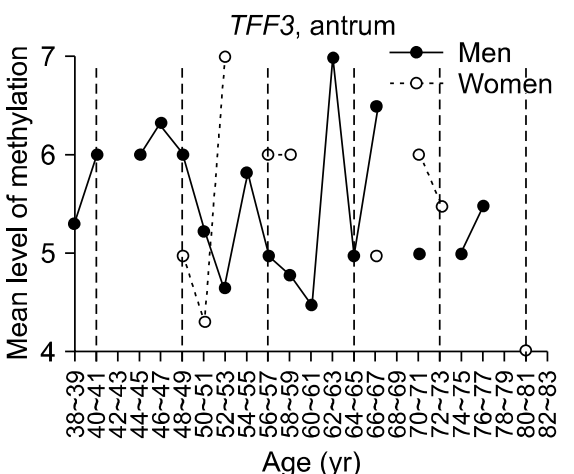

$C D H 1$ and $A R R D C 4$, body

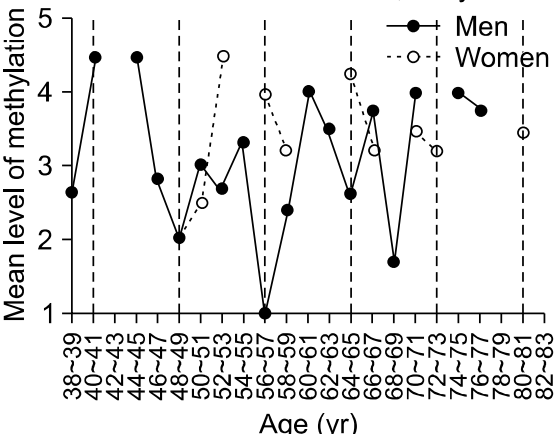

MMP2 and CDKN2A, body

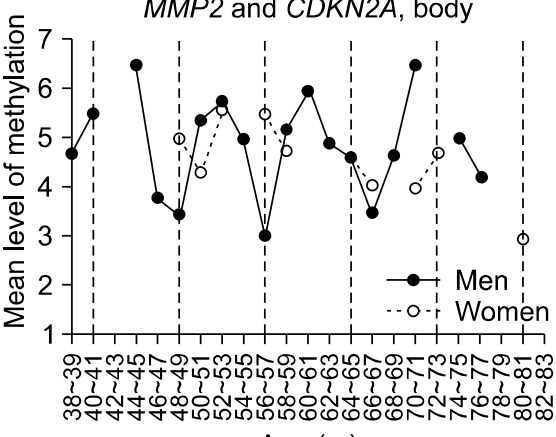

Age (yr)

Fig. 2. Age-related changes in methylation in Helicobacter pylori-negative controls, H. pylori-positive controls, and gastric cancer patients with closed-type atrophy. (A) Individual methylation of TFF2 and TFF3 in the antrum and concurrent methylation of CDH1, ARRDC4, MMP2, and $C D K N 2 A$ in the body are depicted. (B) The mean levels of $C D H 1$ and ARRDC4 methylation in the body are shown in the presence or absence of TFF3 overmethylation in the antrum. TFF3 overmethylation is defined using level 6 as the cutoff point. Samples are collected at 2-year intervals. Vertical dashed lines indicate 8-year intervals after 40 years of age. Horizontal dashed lines indicate level 3 methylation. 
B

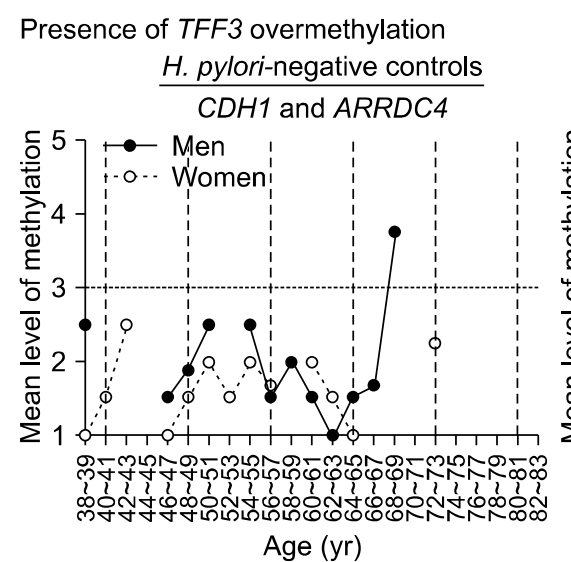

Absence of TFF3 overmethylation

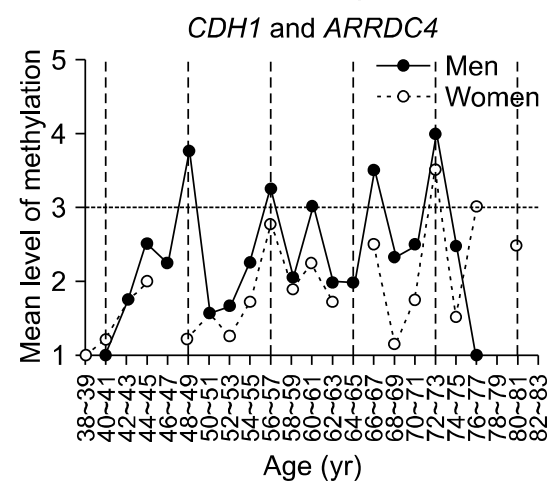

H. pylori-positive controls

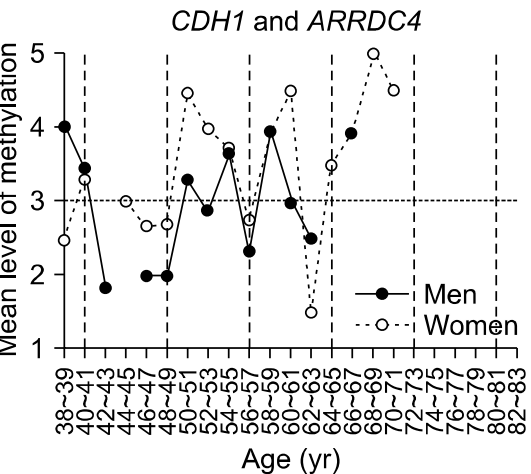

Age (yr)

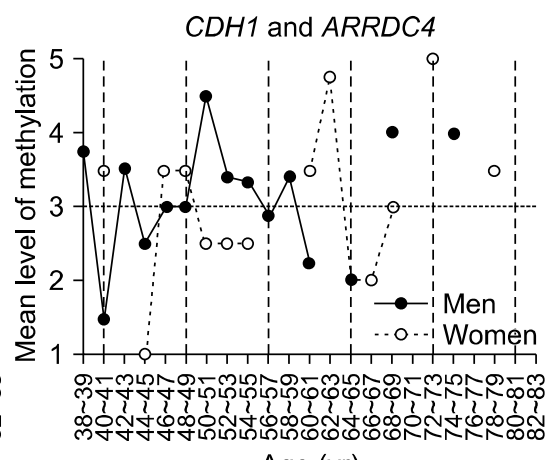

Age (yr)

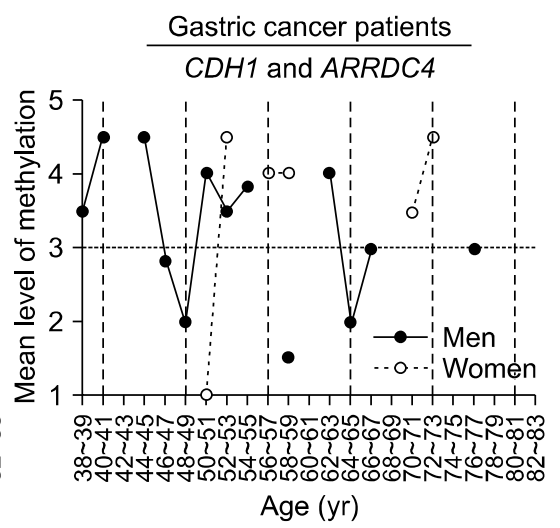

Age (yr)

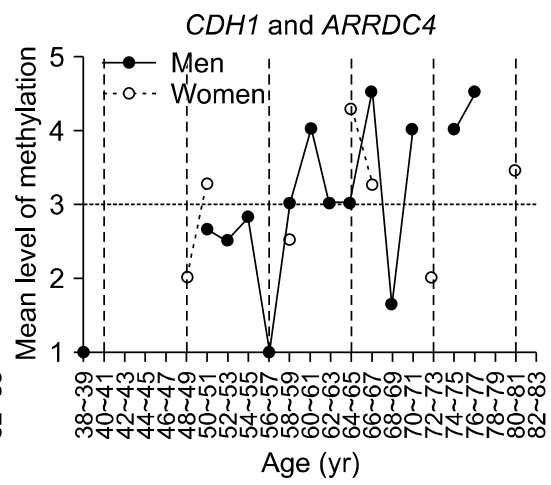

Fig. 2. Continued.

to be impeded under the influence of gastric mucosal atrophy. ${ }^{8}$ In H. pylori-positive controls, TFF3 methylation was increased at 50 to 51 and 56 to 57 age groups in women but not in men (Fig. 2A).

$C D H 1$ and ARRDC4 that are adjacent to Alu retroelements were frequently methylated in the body of $H$. pylori-negative male controls. Mean methylation levels of these two genes were less than 3, with weak increases at ages 46 to 47 and 56 to 57 in the body of $H$. pylori-negative males. Concurrent methylation of $C D H 1$ and ARRDC4 was increased in the 66 to 77 age group in the body of $H$. pylori-negative male controls (Fig. 2A). CDH1 and $A R R D C 4$ were concurrently methylated in the 50 to 51 and 58 to 59 age groups in the body of both H. pylori-positive male and female controls. The mean methylation levels of CDH1 and ARRDC4 troughed at 48 to 49, 56 to 57, and 68 to 69 years of age in male cancer patients; troughs were lower in cancer patients than in $H$. pylori-negative and H. pylori-positive controls (2.0 vs. 2.5 and 2.5 at 48 to 49 years; 1.0 vs. 2.4 and 2.6 at 56 to 57 years; and 1.7 VS. 2.9 and 4.0 at 68 to 69 years).

MMP2 and CDKN2A that are adjacent to LTR retroelements were gradually methylated in the body of both $H$. pylori-negative and $H$. pylori-positive controls. Mean methylation levels of $M M P 2$ and $C D K N 2 A$ troughed at 48 to 49,56 to 57 , and 66 to 67 years of age in the body of men with gastric cancer; the last two troughs were lower in cancer patients than in $H$. pylori-negative and $H$. pylori-positive controls (3.5 vS. 3.8 and 2.8 at 48 to 49 years; 3.0 vs. 4.5 and 3.6 at 56 to 57 years; and 3.5 vs. 4.9 and 6.0 at 66 to 67 years) (Fig. 2A). Concurrent methylation of $M M P 2$ and $C D K N 2 A$ methylation was increased in the 50 to 53 and 58 to 61 age groups in men with gastric cancer, and that was higher than in $H$. pylori-negative and H. pylori-positive male controls $(5.4$ vs. 3.5 and 4.5 at 50 to 51 years; 5.8 vs. 3.3 and 4.9 at 52 to 53 years; 5.2 vs. 
3.2 and 4.7 at 58 to 59 years; and 6.0 vs. 3.4 and 4.4 at 60 to 61 years).

In a previous study, body-site housekeeping genes and antrum-site TFF3 tended to be coincidentally methylated at an early stage. ${ }^{8} C D H 1$ and ARRDC4 body-site methylation were evaluated in the presence and absence of antrum-site TFF3 overmethylation of level $\geq 6$ (Fig. 2B). In $H$. pylori-negative samples from men, four regular peaks of CDH1 and ARRDC4 methylation (level $>3$ ) were observed at 48 to 49, 56 to 57, 66 to 67, and 72 to 73 years of age in the absence of TFF3 overmethylation.

\section{DISCUSSION}

Stomach-specific TFF2 is strongly expressed in gastric glands in both the antrum and body. ${ }^{9}$ Notably, our analysis of normal gastric mucosa samples revealed peaks in the methylation of TFF2 at regular intervals of approximately 8 years, and these peaks corresponded to similar peaks in housekeeping gene methylation in $H$. pylori-negative subjects. These regular peaks in age-related methylation likely represent the periodic replacement of gastric glandular stem cells, some of which may be transformed into cancer stem cells. Housekeeping genes tended to be less methylated in cancer patients than in $H$. pylori-positive controls during the periods of TFF2 methylation peaks. Previous studies of the background mucosa of gastric cancer have demonstrated that insufficient methylation of some housekeeping genes leads to an early unstable stage of stem cell replacement. ${ }^{6,8}$ The appearance of cancer may vary during the extended cancer risk stage during each period of stem cell replacement. The methylation type related to cancer risk is expected to be informative when evaluating the individuals at risk for cancer.

H. pylori-positive subjects had high-level methylation but no periodic methylation changes. H. pylori-induced active inflammation can recruit many new mesenchymal cells around the gastric glands. In such cases, glandular epithelial cells obtained by endoscopic biopsy were contaminated with nearby mesenchymal cells. ${ }^{6}$ Both the mesenchymal and epithelial cells adapting to a new tissue environment can be stabilized by methylation of house- keeping genes, ${ }^{14}$ and the mixture of them in the biopsy specimens may make no cyclic changes and no sex-based differences in the biopsy specimens. Periodic fluctuation in housekeeping gene methylation was more evident in the body than in the antrum of $H$. pylori-negative subjects. In a body with mild inflammation, endoscopic biopsy specimens contain a relatively low number of new mesenchymal cells, which can disclose cyclic methylation changes.

Cyclic TFF2 methylation seems to result from rapid demethylation of transitional-CpG sites influenced by strong gene expression. ' Cyclic TFF3 methylation was somewhat ambiguous in the antrum, possibly because antrum-specific TFF3 expression is weak. ${ }^{9}$ TFF3 and housekeeping genes tended to be concurrently methylated at an early stage and afterward TFF3 methylation decreased at a late stage. ${ }^{8}$ Housekeeping-gene methylation regularly fluctuated in the absence of TFF3 overmethylation in the body of $\mathrm{H}$. pylori-negative subjects. Because there were a low number of new stem cells in $H$. pylori-negative body, housekeeping gene methylation might be increasingly detected as methylation-inducible cells expanded sufficiently and TFF3 methylation decreased.

Retroelements dispersed throughout the genome are thought to be involved in the epigenetic suppression of numerous housekeeping genes during phenotype stabilization of new stem cells. ${ }^{7,14}$ Humans with a long lifespan have higher numbers of SINE retroelements around housekeeping genes than mice with a short lifespan. ${ }^{20}$ This helps to prompt phenotype-stabilizing methylation of new stem cells in humans. Housekeeping genes adjacent to Alu retroelements, human SINEs, are frequently methylated in the gastric mucosa of subjects in their early $40 \mathrm{~s}^{9}$ Previous studies of the background mucosa of gastric cancer have demonstrated that impeded methylation of Alu-adjacent genes leads to an early unstable stage of new stem cells. ${ }^{6,8}$ LTR retroelements also participate in the phenotypic stabilization of stem cells. LTR-adjacent housekeeping gene methylation increased slowly compared to Alu-adjacent gene methylation. ${ }^{9}$ LTR-adjacent genes were more frequently methylated in gastric cancer patients than in $H$. pylori-positive subjects. ${ }^{6,8}$ Sequential methylation changes in Alur-adjacent and LTR-adjacent 
genes may provide information on the formation of cancer-prone stem cells in the gastric mucosa.

Japan and Korea, where gastric cancer is common, conduct biennial endoscopic screening to detect early gastric cancer, ${ }^{21,22}$ as a 2-year screening interval has been proposed to reduce gastric cancer mortality. ${ }^{22,23}$ However, the interval of cancer screening has been determined empirically, and there is no clear evidence as to the optimal screening interval. ${ }^{24}$ In this study, periodic methylation was observed in consistent with the cyclic stabilization of cancer-prone stem cells every 8 years. A previous gastric cancer screening at 5-year intervals revealed a decrease in the incidence of gastric cancer at the first follow-up and an increase at the second follow-up. ${ }^{25}$ The results of the 5-year interval screening, as well as the 8-year-periodic fluctuation in methylation, indicate that the chances of gastric cancer arise at 8-year intervals and that a screening interval $<8$ years is necessary for early cancer detection.

Gastric mucosal atrophy is evaluated using endoscopic examination of the atrophic border and histopathologic examination based on the Sydney system. ${ }^{26}$ These two atrophy-staging systems demonstrate relatively good agreements. ${ }^{26}$ Our previous studies revealed that Aluradjacent methylation was impeded in cancer patients with closed-type atrophy and LTR-adjacent methylation was increased in cancer patients with open-type atrophy compared with controls. ${ }^{6,8}$ This suggests that cancer-related methylation changes are distinct from the progression of gastric mucosal atrophy. Active H. pylori inflammation detected in this study may induce the recruitment of new stem cells intermittently in the gastric mucosa. However, stomach-specific TFF2 methylation peaked at regular intervals in $H$. pylori-positive subjects. Stem cell replacement appears to occur regularly regardless of $H$. pylori infection. Gastric mucosal atrophy and $H$. pylori infection may influence the phenotype-stabilizing methylation during stem cell replacement.

This study had some potential limitations. First, inherent factors may affect methylation patterns. ${ }^{27,28}$ Thus, it is challenging to analyze periodic methylation patterns depending on the family history of gastric cancer patients. Second, because of a relatively small sample size, the au- thors could not conclude the significant decreases in trough methylation of housekeeping genes in cancer patients. Longitudinal studies with a larger sample size are required to investigate periodic methylation levels and the risk of gastric cancer. Third, there may be interobserver differences in the extent of gastric mucosal atrophy based on endoscopic examination. To ensure the reliability of the atrophic border classification, gastric mucosal atrophy was measured repeatedly by two endoscopy specialists. Fourth, the histopathologic types of gastric cancer were not evaluated in this study. In human and mouse gastric cancers, phenotype shift from diffuse to intestinal types is clearly defined. ${ }^{29}$ New stem cells may be unstable at an early stage and acquire gastric stem cell traits at a late stage. Periodically replaced stem cells seem to develop into diffuse-type cancer, followed by intestinal-type cancer, depending on phenotypic stability. Further studies are needed to clarify the relationship between the histologic types of gastric cancer and the phenotype-stabilizing methylation.

In summary, methylation peaks of stomach-specific TFF2 in controls and methylation troughs of housekeeping genes in gastric cancer patients appeared at similar intervals of 8 years. This suggests that new gastric stem cells with high self-renewal capacity replace old stem cells at certain periods rather than irregular periods and that new stem cells displaying impeded housekeeping gene methylation are prone to transform into malignant cells. To our knowledge, stem cell periodicity in terms of gastric cancer evolution has not been previously reported. Even though gastric glandular stem cells were periodically replaced, the initiation of stem cell replacement could be diverse among individuals. Age-related transitional $\mathrm{CpG}$ methylation provides a clue to the initiation point of stem cell replacement. Individuals at high risk for gastric cancer may be effectively distinguished by tracing the phenotype-stabilizing methylation of housekeeping genes after the period of stem cell replacement.

\section{CONFLICT OF INTEREST}

No potential conflict of interest relevant to this article was reported. 


\section{ORCID}

\author{
Sang-Woong Kim (iDhttps://orcid.org/0000-0001-8999-6454 \\ Jung-Hwan Oh (iDhttps://orcid.org/0000-0002-9274-882X \\ Tae Ho Kim (iDhttps://orcid.org/0000-0003-2015-5176 \\ Joon-Sung Kim (iDhttps://orcid.org/0000-0001-9158-1012 \\ Seung-Jin Hong (iDhttps://orcid.org/0000-0001-9456-5579
}

\section{REFERENCES}

1. Okamoto R, Yajima T, Yamazaki M, et al. Damaged epithelia regenerated by bone marrow-derived cells in the human gastrointestinal tract. Nat Med 2002;8:1011-1017.

2. Zuk PA, Zhu M, Ashjian P, et al. Human adipose tissue is a source of multipotent stem cells. Mol Biol Cell 2002;13:4279-4295.

3. Siegmund KD, Marjoram P, Woo YJ, Tavaré S, Shibata D. Inferring clonal expansion and cancer stem cell dynamics from DNA methylation patterns in colorectal cancers. Proc Natl Acad Sci U S A 2009;106:4828-4833.

4. Shibata D. Inferring human stem cell behaviour from epigenetic drift. J Pathol 2009;217:199-205.

5. Houghton J, Morozov A, Smirnova I, Wang TC. Stem cells and cancer. Semin Cancer Biol 2007;17:191-203.

6. Oh JH, Rhyu MG, Jung SH, Choi SW, Kim SI, Hong SJ. Slow overmethylation of housekeeping genes in the body mucosa is associated with the risk for gastric cancer. Cancer Prev Res (Phila) 2014;7:585-595.

7. Rhyu MG, Oh JH, Hong SJ. Species-specific role of gene-adjacent retroelements in human and mouse gastric carcinogenesis. Int J Cancer 2018;142:1520-1527.

8. Oh JH, Rhyu MG, Kim SI, Yun MR, Shin JH, Hong SJ. Gastric mucosal atrophy impedes housekeeping gene methylation in gastric cancer patients. Cancer Res Treat 2019;51:267-279.

9. Hong SJ, Lee HJ, Oh JH, et al. Age-related methylation patterning of housekeeping genes and tissue-specific genes is distinct between the stomach antrum and body. Epigenomics 2013;5: 283-299.

10. Kim YH, Hong SJ, Jung YC, et al. The 5'-end transitional CpGs between the $\mathrm{CpG}$ islands and retroelements are hypomethylated in association with loss of heterozygosity in gastric cancers. BMC Cancer 2006;6:180.

11. Kang MI, Rhyu MG, Kim YH, et al. The length of CpG islands is associated with the distribution of Alu and L1 retroelements. Genomics 2006;87:580-590.

12. Yamada H, Shinmura K, Goto M, et al. Absence of germline mono-allelic promoter hypermethylation of the $\mathrm{CDH} 1$ gene in gastric cancer patients. Mol Cancer 2009;8:63.

13. Shin CM, Kim N, Jung Y, et al. Genome-wide DNA methylation profiles in noncancerous gastric mucosae with regard to
Helicobacter pylori infection and the presence of gastric cancer. Helicobacter 2011;16:179-188.

14. Rhyu MG, Oh JH, Hong SJ. Epigenetic implication of gene-adjacent retroelements in Helicobacter pylori-infected adults. Epigenomics 2012;4:527-535.

15. Wu H, Coskun V, Tao J, et al. Dnmt3a-dependent nonpromoter DNA methylation facilitates transcription of neurogenic genes. Science 2010;329:444-448.

16. Kang MI, Kim HS, Jung YC, et al. Transitional CpG methylation between promoters and retroelements of tissue-specific genes during human mesenchymal cell differentiation. J Cell Biochem 2007;102:224-239.

17. Ji H, Ehrlich LI, Seita J, et al. Comprehensive methylome map of lineage commitment from haematopoietic progenitors. Nature 2010;467:338-342.

18. Kimura K, Takemoto T. An endoscopic recognition of the atrophic border and its significance in chronic gastritis. Endoscopy 1969;1:87-97.

19. Hong SJ, Kang MI, Oh JH, et al. DNA methylation and expression patterns of key tissue-specific genes in adult stem cells and stomach tissues. J Korean Med Sci 2009;24:918-929.

20. Waterston RH, Lindblad-Toh K, Birney E, et al. Initial sequencing and comparative analysis of the mouse genome. Nature 2002;420:520-562.

21. Leung WK, Wu MS, Kakugawa Y, et al. Screening for gastric cancer in Asia: current evidence and practice. Lancet Oncol 2008;9:279-287.

22. Jun JK, Choi KS, Lee HY, et al. Effectiveness of the Korean National Cancer Screening Program in reducing gastric cancer mortality. Gastroenterology 2017;152:1319-1328.e7.

23. Park $\mathrm{CH}$, Kim EH, Chung H, et al. The optimal endoscopic screening interval for detecting early gastric neoplasms. Gastrointest Endosc 2014;80:253-259.

24. Kim EH, Park CH. Screening endoscopy for gastric cancer: time for quality control. Transl Gastroenterol Hepatol 2017;2:79.

25. Riecken B, Pfeiffer R, Ma JL, et al. No impact of repeated endoscopic screens on gastric cancer mortality in a prospectively followed Chinese population at high risk. Prev Med 2002;34: 22-28.

26. Liu Y, Uemura N, Xiao SD, Tytgat GN, Kate FJ. Agreement between endoscopic and histological gastric atrophy scores. J Gastroenterol 2005;40:123-127.

27. Song JH, Kim JH, Shim SG, et al. Promoter methylation of helicase-like transcription factor in gastric cancer. Korean J Helicobacter Up Gastrointest Res 2006;6:29-34.

28. Chang ZW, Dong L, Qin YR, Song M, Guo HY, Zhu QL. Correlations between gastric cancer family history and $\mathrm{ROBO} 2$ and RASSF2A gene methylations. J Cancer Res Ther 2016;12: 597-600.

29. Tatematsu M, Tsukamoto T, Inada K. Stem cells and gastric cancer: role of gastric and intestinal mixed intestinal metaplasia. Cancer Sci 2003;94:135-141. 